\title{
Elderly people taking non-steroidal anti-inflammatory drugs are unlikely to have excess renal impairment
}

\author{
Josephine Allred, Wendy Wong and Kalman Kafetz \\ Department of Medicine for Elderly People, Whipps Cross Hospital, London E11 INR, UK.
}

\begin{abstract}
Summary: The importance of possible adverse effects on renal function of non-steroidal antiinflammatory drugs has been widely discussed. Elderly people have been thought to be particularly at risk. We therefore studied simple indices of renal function and plasma potassium in 54 patients with a mean age of 85 years, 27 taking these drugs and 27 controls. Twenty five of our 54 patients were also taking diuretics. Non-steroidal anti-inflammatory drugs did not affect renal function or plasma potassium in these patients.
\end{abstract}

\section{Introduction}

Non-steroidal anti-inflammatory drugs (NSAIDs) are an effective treatment for arthritic and musculoskeletal pain and are therefore widely used by elderly patients. However renal side effects of these drugs are being increasingly described, ${ }^{1}$ It has been suggested that elderly patients are particularly at risk and the risk is increased if patients are also taking diuretics. ${ }^{2,3}$

Data from the Boston Collaborative Drug Surveillance Program suggested that clinical problems may be limited ${ }^{4}$ but this data by itself may not be enough to show that elderly people taking the drugs are unlikely to have excess renal impairment. ${ }^{5}$ This prompted us to look at a group of elderly patients, some of whom were taking NSAIDs, to see if there was any effect on renal function and serum potassium. Some of these patients, both in the treatment and non-treatment groups, were also taking diuretics.

\section{Patients and methods}

We studied 54 patients attending our day hospitals. All were women to avoid any confounding effect of prostatism on renal function in men. ${ }^{6}$ They had been attending for at least two weeks. Twenty seven consecutive new patients taking NSAIDs and 27 controls, taken consecutively during the time the patients were collected, were studied. The day hospitals function as multi-disciplinary outpatient clinics and patients may often attend in clinically unstable conditions. Twenty seven had been taking NSAIDs for at least 3 weeks; 12

Correspondence: K. Kafetz B.Sc., M.R.C.P. (UK).

Accepted: 6 February 1989. were taking ibuprofen, 6 were taking fenbufen, 3 were taking naproxen, 2 were taking flurbiprofen and one each were taking ketoprofen, azapropazone and piroxicam. One patient was taking both indomethacin and ibuprofen. The characteristics of the two groups are shown in Table I. Distribution of age, blood pressure (BP) and blood sugar were the same in the two groups. 'Fifteen of the controls and 10 of the patients taking NSAIDs were also taking diuretics.

Table I Findings in patients on non-steroidal antiinflammatory drugs and a control group

\begin{tabular}{|c|c|c|c|c|c|}
\hline & \multicolumn{2}{|c|}{$\begin{array}{l}\text { Patients } \\
\text { (27) }\end{array}$} & \multicolumn{2}{|c|}{$\begin{array}{l}\text { Controls } \\
\text { (27) }\end{array}$} & \multirow{2}{*}{$\begin{array}{l}95 \% \text { confidence } \\
\text { interval for } \\
\text { the difference }\end{array}$} \\
\hline & Mean & s.d. & Mean & s.d. & \\
\hline $\begin{array}{l}\text { Age } \\
\text { (years) }\end{array}$ & 84 & 7 & 85 & 7 & \\
\hline $\begin{array}{l}\text { Systolic BP } \\
(\mathrm{mmHg})\end{array}$ & 132 & 52 & 126 & 32 & \\
\hline $\begin{array}{l}\text { Diastolic BP } \\
(\mathrm{mmHg})\end{array}$ & 72 & 28 & 74 & 20 & \\
\hline $\begin{array}{l}\text { No. of } \\
\text { people on } \\
\text { diuretics }\end{array}$ & 10 & & 15 & & \\
\hline $\begin{array}{l}\text { Blood glucose } \\
(\mathrm{mmol} / 1)\end{array}$ & 5.8 & 3.4 & 6.2 & 5.3 & \\
\hline $\begin{array}{l}\text { Urea } \\
(\mathrm{mmol} / 1)\end{array}$ & 8.5 & 4.1 & 8.1 & 3.9 & -1.8 to +2.5 \\
\hline $\begin{array}{l}\text { Creatinine } \\
(\mu \mathrm{mol} / \mathrm{l})\end{array}$ & 106 & 31 & 101 & 3.8 & -13.3 to +24.4 \\
\hline $\begin{array}{l}\text { Potassium } \\
(\mathrm{mmol} / \mathrm{l})\end{array}$ & 4.3 & 0.5 & 4.3 & 0.5 & -0.3 to +0.2 \\
\hline
\end{tabular}




\section{Results}

The results are shown in Table I. There was no apparent difference between subjects and controls. The $95 \%$ confidence intervals for the differences suggest that adequate numbers of patients were studied and that a real difference between the two groups was not missed. Even if there was a difference and an increase in urea, creatinine and potassium in the patients on NSAIDs was present, this increase would at the most be $2.5 \mathrm{mmol} / 1,24 \mu \mathrm{mol} / 1$ and 0.2 mmol/1 which would have no clinical consequence. Analysis of variance showed no difference between the subjects on diuretics, subjects without diuretics, controls on diuretics and controls without diuretics ( $F=1.61$ with $3 / 50$ degrees of freedom). There was a suggestion that diuretics were associated with a slightly increased blood urea whether or not NSAIDs were taken. The 25 patients on diuretics had a mean blood urea of $9.5 \mathrm{mmol} / 1$ (s.d. 5.1) and the 29 patients not (s.d. 3.2). The $95 \%$ confidence intervals for the difference were +0.8 to $+4.2(P=0.04)$.

\section{Discussion}

The two main renal side effects of NSAIDs are renal failure and hyperkalaemia. The suggested mechanisms for both are associated with the inhibition of prostaglandin synthesis by NSAIDs. When renal function is normal there is no dependence on prostaglandins. However, when there is renal hypoperfusion, circulating noradrenaline and angiotensin cause renal vasoconstriction aggravating the hypoperfusion and lead to a decline in renal function. Normally this is balanced by these agents also promoting secretion of prostaglandins, especially $\mathrm{PGE}_{2}$ and $\mathrm{PGI}_{2}$ (prostacyclin) from arachidonic acid in lipid plasma membranes via cyclo-oxygenase. This balancing process may be blocked by NSAIDs. ${ }^{7-9}$ When renal function is normal, it is not prostaglandin dependent unless the patient is salt depleted as can occur when diuretics are taken. ${ }^{10}$ However, when renal function is abnormal it may be prostaglandin dependent whatever the mechanism of renal impairment and even in the absence of salt or volume depletion. ${ }^{11}$ The renal impairment of normal ageing is caused by a reduction taking diuretics had a mean blood urea of $7.3 \mathrm{mmol} / 1$

in blood flow due to sclerotic obliteration of the preglomerular arteriole ${ }^{2,13}$ and may be dependent on prostaglandins. ${ }^{14}$ NSAIDs have been suggested as $a$. cause of chronic renal failure in the elderly. ${ }^{15}$

The mechanism of NSAID-induced hyperkalaemia is said to be related to prostaglandin-dependenE vasodilatation of the afferent arteriole affecting the baroreceptors modulating renin release. ${ }^{16}$ Plasm雨 potassium rises with age. ${ }^{17}$

Age changes in metabolism of NSAIDs arês relatively minor. Protein binding tends to decrease $\vec{\rho}$ volumes of distribution tend to show a small increaseand clearance, especially of renally excreted drugs $\omega$ may fall. Any increased propensity of the elderly to suffer adverse reactions to NSAIDs cannot be readily explained on a pharmacokinetic basis. ${ }^{18}$

This study of patients whose mean age was well ovee 80 shows that in normal use NSAIDs are very unlikelyo to affect renal function in elderly people. The mean values of urea and creatinine were within the normat range for this age group. ${ }^{19}$ The fairly tight confidences intervals for the differences compensate considerably for the relatively small number of patients in eacho group. An effect in men rather than women is noef excluded although this would be more difficult tor demonstrate because confounding prostatism is com $=$ mon.

While diuretics may have had some effect on resalo function, this was not exaggerated in the patients NSAIDs. Although renal function deteriorates with age, this study suggests that function of the normaP ageing kidney is not dependent on prostaglandins The use of diuretics by our patients may have causeco a slight further rise in blood urea. However, even in this circumstance, the disturbance in renap haemodynamics was not such that there was dependence on prostaglandin synthesis and so furthen impairment when patients were taking NSAIDs:Similarly there was no effect on plasma potassium.

Nevertheless the results of this study should not be taken to suggest that NSAIDs are safe in elderly patients who are clinically dehydrated or who have renal impairment more than is usual in normal ageing None of the patients was taking mefenamic acid whicho can cause dehydration through diarrhoea with? associated renal failure. ${ }^{20}$ Most of the patients weres taking NSAIDs with short half lives and routine use of the drugs with longer half-lives may be undesirable. o

\section{References}

1. Garella, S. \& Matarese, R.A. Renal effects of prostaglandins and adverse clinical effects of non-steroidal anti-inflammatory agents. Medicine (Baltimore) 1984, 63: 165-181.
2. Linton, A.L. Adverse effects of NSAIDs on renal $\stackrel{\varrho}{+}$ function, Can Med Assoc J 1984, 131: 189-191.

3 Orme, M.L'E. Non-steroidal anti-inflammatory drugsō and the kidney. $\mathrm{Br}$ Med J, 292: 1621-1622. 
4. Fox, D.A., \& Jick, H. Non-steroidal anti-inflammatory drugs and renal disease. JAMA 1984, 251: 1299-1300.

5. Schrier, R.W. \& Henrich, W.L. Non-steroidal antiinflammatory drugs: caution still indicated. JAMA 1984, 251: $1301-1302$.

6. Olbrich, O., Woodford-Williams, E., Irvine, R.E. \& Webster, D. Renal function in prostatism. Lancet 1957, i: $1322-1324$.

7. Stillman, M.T., Napier, J.N. \& Blackshaw, J.L. Adverse effects of non-steroidal anti-inflammatory drugs on the kidney. Med Clin North Am 1984, 68: 371-385.

8. Pirson, Y. \& Van Ypersele de Strihou, C. Renal side effects of non-steroidal anti-inflammatory drugs: clinical relevance. Am J Kidney Dis 1986, 8: 338-344.

9. Dominguez-Gil, A., Garcia, M.J. \& Navarro, A.J. Pharmokinetics in the elderly. In: Macias Nunez, J.F. \& Cameron, J.S. (eds) Renal Function and Disease in the Elderly. Butterworth, London, 1987, pp. 184-203.

10. Clive, D.M. \& Stoff, J.S. Renal syndromes associated with nonsteroidal anti-inflammatory drugs. $N$ Engl $J$ Med 1984, 310: 563-572.

11. Ciabattoni, G., Cinotti, G.A., Pierucci, A. et al. Effects of sulindac and ibuprofen in patients with chronic glomerular disease. $N$ Engl J Med 1984, 310: 279-283.

12. Takazdakura, E., Sawabu, N., Handa, A., Takada, A., Shinoda, A. \& Takeuchi, J. Intrarenal vascular changes with age and disease. Kidney Int 1972, 2: 224-230.

13. McLachan, M. Anatomical, structural and vascular changes in the aging kidney. In: Macias Nunez, J.F. \& Cameron, J.S. (eds) Renal Function and Disease in the Elderly. Butterworth, London, 1987, pp. 3-26.
14. Bender, W.L., Whelton, A., Beschomer, W.E., Darnish, $\frac{3}{\pi}$ M.O., Hall Craggs, M. \& Solez, K. Interstitial nephritis, @ proteinuria and renal failure caused by non-steroidal $\subseteq$ anti-inflammatory drugs. Am J Med 1984, 176: 1006-1112.

15. Adams, D.H., Howie, A.J., Michael, J. et al. Non-steroidal anti-inflammatory drugs and renal failure. Lancet 1986, i: 997-1001.

16. Carmichael, J. \& Shankel, S.W. Effects of nonsteroidal anti-inflammatory drugs on prostaglandins and renal function. Am J Med 1985, 78: 992-1000.

17. McPherson, K., Healy, M.J.R., Flynn, F.V., Piper, $\vec{\circ}$ K.A.J. \& Garcia-Webb, P. The effect of age, sex and other factors on blood chemistry in health.. Clin Chim Acta 1978, 84: 373-397.

18. Woodhouse, K.W. \& Wynne, H. The pharmacokinetics of non-steroidal anti-inflammatory drugs in the elderly. Clin Pharmacokinet 1987, 12: 111-122.

19. Leask, R.G.S., Andrews, G.R. \& Caird, F.I. Normal ơ values of sixteen blood constituents in the elderly. Age Ageing 1973, 2: 14-23.

20. Taha, A., Lenton, R.J., Murdoch, P.S. \& Peden, N.R. W Non-oliguric renal failure during treatment with 0 mefenamic acid in elderly patients; a continuing problem. $\mathrm{Br}$ Med J 1985, 291: 661-662. 